\title{
ONU no século XXI
}

A ORGANIZAÇÃo das Nações Unidas (ONU) nasceu após o segundo conflito mundial para salvar as gerações futuras do flagelo das guerras e preservar a segurança internacional. A Assembléia Geral da instituição iniciou sua sessão de 2008, em setembro último, abordando as crises que o mundo tem sido incapaz de resolver. A crise financeira, a fome, a intensificação das mudanças climáticas, guerras no Iraque, no Afeganistão e na Geórgia. Atentados terroristas de Islamabad, a pobreza e a febre amarela foram outros temas abordados. Todos os 192 países-membros têm direito a palavra, mas apenas o Conselho de Segurança, integrado por cinco membros permanentes com direito a veto e dez membros rotativos, detém efetivamente poder executivo. Foi esse órgão o responsável pela adoção, em 22 de maio de 2003, da Resolução 1843 que, no seu item $8^{\circ}$, diz:

Solicita ao Secretário-Geral que nomeie um Representante Especial para o Iraque, cujas responsabilidades, a exercer de forma independente, consistirão em submeter periodicamente ao Conselho relatórios sobre as atividades que realize nos termos da presente resolução, coordenar as atividades das Nações Unidas no processo pós-conflito no Iraque, assegurar a coordenação entre as Nações Unidas e organismos internacionais envolvidos na assistência humanitária e nas atividades de reconstrução no Iraque e, em coordenação com a Autoridade, prestar assistência ao povo iraquiano.

Essas responsabilidades propiciariam condições favoráveis à criação de insti- tuições nacionais e locais que possibilitassem a formação de um governo representativo, a reconstrução econômica, a criação de condições para um desenvolvimento sustentável, a proteção dos direitos humanos, a recuperação das forças da polícia civil iraquiana e, finalmente, o incentivo aos esforços internacionais para promover uma reforma jurídica.

Três meses após a adoção daquela resolução, foi assassinado o representante especial do secretário-geral Kofi Annan. Sérgio Vieira de Mello, sem a devida proteção e apoio, mas com a difícil tarefa de abreviar os conflitos e tentar a restauração de uma nação em pedaços, morreu após horas de agonia, em pleno cumprimento do seu dever. Tombou em Bagdá, vítima do terror jihadista, quando iniciava esforços para a construção de uma legítima autoridade iraquiana.

O livro de Samantha Power, $O$ bomem que queria salvar o mundo, descreve a trajetória e confirma o legado de Sérgio, que se distinguiu mundialmente pela crença inabalável no diálogo e na democracia, mesmo em condições agudamente desfavoráveis. Foi essa crença que o animou nas complexas missões em Moçambique, no Kosovo, no Timor Leste, no Sudão, no Líbano e outras regiões tragicamente dominadas pelo caos. Unindo ação e pensamento, ele demonstrou, nessas literais provas de fogo, a sua grande capacidade agregadora e uma eficiência administrativa também fora do comum. Tendo sempre, como princípio orientador, o culto permanente aos valores da liberdade. 


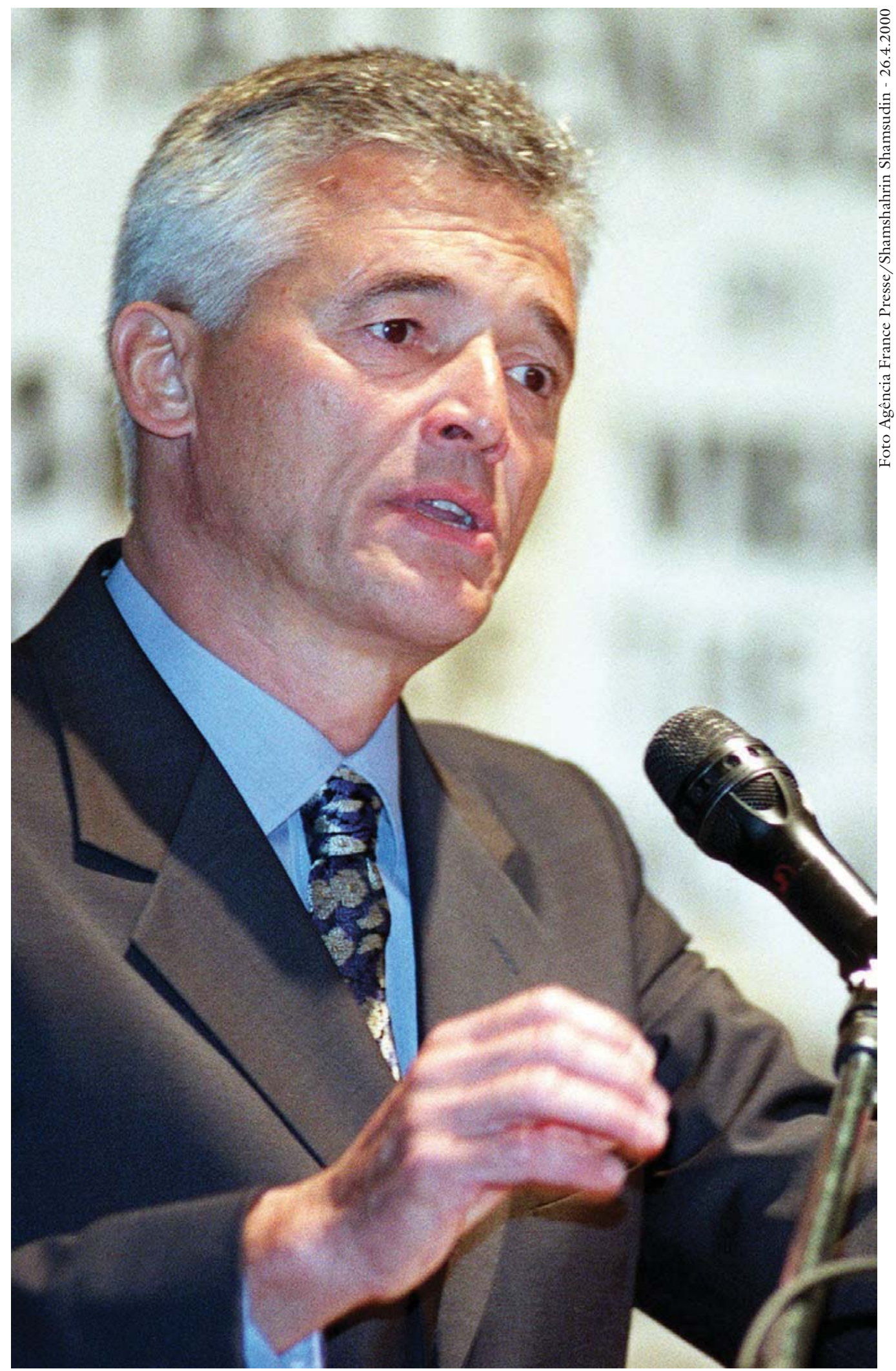

Sérgio Vieira de Mello (1948-2003). 
A obra publicada no Brasil pela Companhia das Letras retoma o enfoque de livros precedentes, como o de JeanClaude Buhrer \& Claude B. Levenson, Sergio Vieira de Mello, un espoir foudroyé, e o de George Gordon-Lennox \& Annick Stevenson, Sergio Vieira de Mello: un homme exceptionnel, ambos lançados em 2004. Apenas um ano depois da tragédia em Bagdá, esses dois autores já se detinham no percurso humano e profissional do exemplar construtor da cidadania e dos direitos humanos em territórios conflagrados. Além de adotar o mesmo enfoque, Samantha Power também leva o leitor a recordar o premiado filmeverdade $A$ caminho de Bagdá (2004), da jornalista Simone Duarte, que descreveu com sobriedade a vida desse influente servidor público internacional, assim como outro documentário, Timor Lorosae - o massacre que o mundo não vin (2001), de Lucélia Santos, que retratou os sofrimentos dos timorenses e a história dos conflitos naquele pequeno país, antes da intervenção das Nações Unidas, liderada por Sérgio Vieira de Mello. No capítulo em que Samantha revive o dia do atentado, o leitor lembrará o documentário Pulled from the Rubble (Retirado dos escombros) (2005), de Margaret Loescher, cujo pai perdeu as pernas e parte do braço, sendo um dos poucos sobreviventes daquele brutal acontecimento.

Apesar de algumas concessões aparentemente feitas para viabilizar o roteiro de um novo filme já contratado, o livro de Samantha Power tem méritos indiscutíveis. Entre estes, a análise densa das limitações do atual sistema multilateral, uma dramática descrição das poucas horas transcorridas entre a explosão do escritório da ONU e a morte de Sérgio

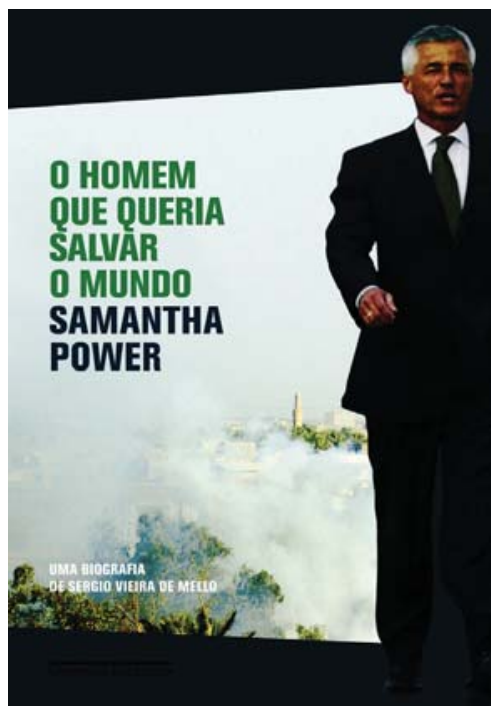

POWER, Samantha. O bomem que queria salvar o mundo.

São Paulo: Cia. das Letras, 2008. 688p.

Vieira de Mello, além das lições oferecidas pelos fatos e tratadas com grande competência por uma ganhadora do Prêmio Pulitzer em 2003. Em síntese, valiosa contribuição para a história da ONU e para repensar o seu papel no contexto do século XXI.

Jornalista e especialista em relações internacionais, a autora sublinha a importância da ONU, mas também evidencia a lentidão do seu Conselho de Segurança em face de ameaças graves à segurança mundial, bem como a impotência, nesses fatos, do secretário-geral. Inércia que decorre, em parte, de perspectivas distintas, quase opostas, sobre os objetivos dessa organização multilateral. Para uns, a missão do Conselho de Segurança da ONU se limita a fazer o que as grandes potências (em especial os Estados Unidos) são incapazes de fazer sozinhas. Para outros, cabe à ONU defender a indivisibilidade de três valores fundamentais: viver sem medo, viver 
sem miséria e viver com dignidade. Em outras palavras, cabe-lhe promover a construção da paz, do desenvolvimento e dos direitos humanos. É nesse espaço contraditório que o secretário-geral e sua equipe devem cumprir as determinações nem sempre claras do Conselho de Segurança.

Reconhecida pesquisadora do multilateralismo, Samantha Power demonstra que boa parte da diplomacia norte-americana entende as Nações Unidas como um instrumento para viabilizar seus interesses estratégicos. Foi esse um dos motivos que levaram ao mandato contido na Resolução 1843 do Conselho de Segurança, que buscava, paradoxalmente, conciliar a missão do representante da ONU (acelerar a transferência do poder aos iraquianos) e os interesses da força militar ocupante, liderada pelo embaixador norte-americano Paul Bremer num território historicamente abalado pelas rivalidades entre facções religiosas.

Tendo por pano de fundo esse quadro tenso e perigoso, com base em entrevistas e extensas pesquisas, o livro confirma a teia criminosa que envolveu a tragédia. Como sabemos, o movimento jihadista, antes liderado por Abu Musab Al Zarqawi, foi o principal responsável. Coube a outro fanático, Abu Omar Al-Kurdi, construir a bomba colocada no caminhão que explodiu, em 19 de agosto de 2003, destruindo o Canal Hotel. O objetivo dos terroristas era minar a formação pela ONU de um Conselho de Governo no Iraque, tarefa construtiva e apaziguadora, na qual Sérgio Vieira de Mello estava diretamente engajado. Também restou provado que Fahdal Nassim, um argelino suicida, dirigiu o caminhão carregado de explosivos detonado ao lado da representação da ONU.
O líder terrorista Abu Musab Al Zarqawi, morto em junho de 2006, era um jordaniano que combateu no Afeganistão. Tinha se declarado mentor desse atentado que provocou a morte de 22 pessoas e 167 feridos, a maioria funcionários das Nações Unidas. Foi também responsável pelos ataques às mesquitas xiitas em Bagdá e Kerbala, matando 181 pessoas, e da mesquita do Imã Ali, que levou a vida de 105 pessoas. Ele arquitetou a campanha para inibir a construção de um poder local em condições de assumir as rédeas do processo político no Iraque. Assim atuava por integrar o fundamentalismo sunita que não reconhece os xiitas como verdadeiros muçulmanos. Essas agressões assassinas continuam enlutando centenas de famílias.

Samantha Power respalda seu texto no relatório sobre as condições de segurança no escritório da ONU em Bagdá, o qual concluiu que a instituição foi incapaz de evitar os riscos para o trabalho previsto. A pesquisadora lança mão do comunicado do Grupo de Estudos das Responsabilidades pela Segurança no Iraque, criado em novembro de 2003 pelas Nações Unidas. Lembra não ter havido missão precursora da ONU para avaliar as condições no Iraque, antes da chegada dos primeiros agentes humanitários. É dito, ainda, que os critérios da gestão de segurança aplicados à sede da ONU em Bagdá eram totalmente deficientes, o que levou o secretário-geral a adotar sanções punitivas, mas tardias. Resta o conforto de que novas tragédias podem ser evitadas.

A biógrafa reitera, nesses pontos, aspectos abordados em outro livro, Mission inachevée, de Gabriel Pichon, publicado em 2005. Pichon foi auxiliar da ONU em Bagdá e recordou a precarie- 
dade das medidas de segurança proporcionadas aos integrantes da representação e dos recursos de imediato socorro em casos de emergência. Basta lembrar que do horário da explosão terrorista até a remoção do corpo do Sérgio Vieira de Mello passaram-se mais de quatro horas, das quais em mais de duas ele esteve com vida e consciente.

Olhando para o século XXI que se inicia, quais lições foram recolhidas pela comunidade internacional e pela ONU? A autora se debruça sobre essa e demais perguntas desde então formuladas. Qual é o papel da ONU em zonas conflitadas, onde seus quadros correm riscos de morte? Como conciliar a ajuda multilateral de caráter humanitário e os interesses nacionais dos Estados? Como distinguir as forças de paz da ONU das forças militares ocupantes de um país ou de uma região?

Respostas a essas perguntas encontram-se em artigo publicado pelo Institut Universitaire d'Étude du Développement, de Genebra, sob o título Les dix enseignements $d u$ Timor (2003). Com base na sua experiência no Timor Leste, Sérgio Vieira de Mello expôs os riscos a enfrentar e os deveres das Nações Unidas com a organização do novo Estado.

Nessa exposição, sempre advertindo contra a fácil tentação do improviso em administração, ele insistiu no desmantelamento por tropas internacionais do que chamou "forças da sombra". Forças que eram no Timor as milícias clandestinas e, depois, em Bagdá, os comandos suicidas que o mataram. Ao defender um adequado recrutamento de recursos humanos aproveitáveis nos tribunais e grupos de polícia, como forma de anular o veneno da incompetência, relatou iniciativa marcante de sua gestão, que foi a rigorosa paridade entre homens e mulheres no corpo funcional do novo Estado. Foi sublinhada fortemente a inércia da comunidade internacional, que muitas vezes retardou o aporte de dotações. Falhas da ONU e dos paísesmembros não foram omitidas, as quais, coincidentemente, causaram a sua morte em Bagdá.

Para os aspirantes à carreira diplomática e estudiosos das relações internacionais, Sérgio Vieira de Mello deixou o exemplo da aquisição permanente do conhecimento. Ele não foi apenas o homem de decisões acertadas, mas um intelectual dedicado à filosofia e à história, duas chaves-mestras para a compreensão das relações internacionais. Mirem-se, portanto, as lideranças em formação no pensamento desse homem excepcional sobre questões como direitos humanos, defesa da paz, combate à exclusão, papel da mulher na sociedade e reconstrução de comunidades arruinadas pela violência.

Até nos derradeiros minutos de vida, Sérgio Vieira de Mello preocupava-se com o destino do multilateralismo. É comovedor o depoimento de um técnico em emergências médicas que esteve perto dele e o avistou, quase soterrado por toneladas de cimento, a formular um apelo: "Don't let them pull the UN out!" ["Não os deixe expelir a ONU do Iraque!"].

Sérgio Vieira de Mello, desde o início de sua jornada profissional, empenhouse na construção de uma identidade baseada em valores humanos fundamentais. Em Genebra, ouvi de outro humanista, Jean Halperin, que Sérgio começou a trabalhar como simples redator de correspondência na Comissão das Nações Unidas para os Refugiados. Aceitou essa 
iniciação modesta, entre outros motivos, porque precisava suprir o próprio sustento. Desde então, como demonstram seus textos da juventude à maturidade, ele insistiu na visão universalista de que a espécie humana constitui uma comunidade única e indivisível. Esse foi outro exemplo que ele deixou aos seus jovens compatriotas.

A biografia escrita por Samantha Power, na boa trilha de outros livros e documentários, reconstitui o percurso de um obstinado guerreiro da paz, que usou a palavra como instrumento de persuasão ou de combate. Ele inscreveu o seu nome no panteão dos heróis contemporâneos e receberá, para sempre, a grata reverência de toda a humanidade.

Jacques Marcovitch é professor do Instituto de Relações Internacionais e da Faculdade de Economia, Administração e Contabilidade, ambas da Universidade de São Paulo. Organizador da obra Sérgio Vieira de Mello: pensamento e memória (Edusp/Saraiva, 2004) e curador do portal www.usp.br/svm @ - jmarcovi@usp.br 